\title{
NATIONAL LEVEL INVENTORY OF COFFEE PLANTATIONS USING HIGH RESOLUTION SATELLITE DATA
}

\author{
R. Hebbar ${ }^{1}$, H.M. Ravishankar ${ }^{1}$, Shivam Trivedi ${ }^{1}$, V.B. Manjula ${ }^{1}$, Nagashree Mohan Kumar ${ }^{1}$, D.S. Mukharib ${ }^{2}$, J. Kishor Mote $^{2}$, S. \\ Sudeesh $^{2}$, Uday Raj $^{1}$, Y. Raghuramulu ${ }^{2}$, K. Ganesha Raj ${ }^{1}$ \\ ${ }^{1}$ Regional Remote Sensing Centre, NRSC/ISRO, Marathahalli, Bengaluru, India (hebbar_kr, raviskankar_hm, shivamtrivedi, \\ manjula_vb, nagashree_tr, udayraj, ganeshraj)@nrsc.gov.in \\ ${ }^{2}$ Central Coffee Research Institute, Balehonnur, Karnataka, India (dr.coffeeboard@nic.in) (mukharib, sudheeshses, \\ kishormote56)@gmail.com
}

Commission III, WG III/10

KEY WORDS: Coffee, traditional \& non-traditional regions, inventory, high resolution, spectral signature, classification, India

\begin{abstract}
Coffee is the second most traded commodity in the world and its production has implications in both international and domestic economy. It is an important commercial crop of India and hence, reliable acreage and production estimation is most essential for taking up policy decisions. The coffee growing regions in India are mainly confined to the traditional South Indian states (Karnataka, Kerala and Tamil Nadu) and partly in non-traditional regions (Andhra Pradesh and Odisha) while to a smaller extent in North-Eastern states. Interpretation and mapping of coffee plantations using satellite data is quite challenging due to the diverse and complex cultivation practices. In the present study, multi-resolution and multi-source data was utilized for mapping of coffee plantations in the country. Temporal LISS-III $(24.0 \mathrm{~m})$ data was used for characterizing the phenology of coffee and other competing plantation crops for selection of optimal high resolution satellite (HRS) datasets. Accordingly, Cartosat-1 (2.5m) and Resourcesat LISS-IV multispectral $(5.0 \mathrm{~m})$ datasets corresponding to February-April months were utilized. The spectral signature of coffee plantations is determined by the age category of coffee plantations, varietal difference, density \& composition of shade trees along with terrain features like slope and aspect. The plantations manifested in different tones of red and mottled texture on the multispectral image. Object oriented classification approach showed encouraging results in homogenous \& contiguous areas but showed poor mapping accuracy in heterogeneous regions due to complex spectral signature and varying texture. Thus, a combination of digital and visual interpretation techniques were used for mapping of coffee plantations depending on the suitability. Feature space optimization function was used for selection of object parameters and 14 image features consisting of mean spectral values, standard deviation, NDVI, geometry and contextual parameters were used for classification of coffee plantations using Support Vector Machine (SVM). In case of small holdings and heterogeneous areas, interactive visual interpretation of HRS data at 1:5,000 scale using tone, texture, shape and terrain characteristics was carried out for mapping of coffee plantations with the help of ground truth and field experience of Liaison Officials of Coffee Board. Post-interpretation field verification/validation of the interpreted maps was carried out for the accuracy assessment and the overall mapping accuracy of better than 90.0 per cent was achieved in the study. Total area under coffee plantations was about 4.41 lakh ha (excluding N-E states). This is the first study in the country to generate coffee map at national level for creation of baseline geospatial database which could be updated periodically. Suitability analysis using pedo-climatic and terrain parameters is being carried to promote the coffee cultivation in the nontraditional regions. Further research efforts are necessary for varietal discrimination and modelling of pests and diseases which is critical input for production estimation.
\end{abstract}

\section{INTRODUCTION}

Coffee crop is the second most traded commodity in the world, second only to the crude oil production (Bernardes et.al, 2012). Over the last few decades, Indian coffee industry has made rapid strides and earned a distinct identity on the coffee scenario of the world. India's current share of world coffee production is around $3.67 \%$, while its share in global exports is about $4.53 \%$. The final crop estimate based on crop harvest data for the year 2017-18 is about 316,000 MT. Coffee cultivation was deregulated during 1996 and there is a sizable increase in the area under coffee cultivation in southern India (Coffee Board, 2018). In India, the cultivation of coffee is confined mainly to Karnataka, Kerala and Tamil Nadu and partly in Andhra Pradesh, Orissa and to a smaller extent in north-eastern states. Coffee growing regions in India have diverse climatic conditions, which are well suited for cultivation of different varieties of coffee. Some regions with high elevations are ideally suited for growing Arabicas of mild quality while those with warm humid conditions are best suited for Robustas (Coffee Board, 2018). Certain modern as well as traditional systems of coffee production may play an important conservation role, not only for favouring species conservation and providing numerous environmental services, but also because coffee is usually grown on an elevation gradient that represents key biological transition zones (Moguel and Toledo, 1999). Coffee cultivation, particularly when practiced with shade or traditional systems, has been recognized for its importance in promoting conservation of biodiversity. Shade trees in coffee system prevent soil erosion on a sloping terrain; they enrich the soil by recycling nutrients from deeper layers, protect the coffee plant from seasonal fluctuations in

\footnotetext{
* Corresponding author
} 
temperature, and play host to diverse flora and fauna (Perfecto et al. 1996; Komar, 2006; Coffee Board, 2018).

With advancements in space technology, availability of high resolution data and advanced processing techniques, the remote sensing technique has become a powerful tool for mapping and monitoring of natural resources. The use of remote sensing data for inventory of coffee plantations has proved to be promising (Miguel et al., 2012). However, the process for getting information from satellite data can be complex because it depends on spectral, temporal and spatial resolutions from the sensor used (Bernardes et.al, 2012). Notwithstanding the economic and environmental importance of coffee plantations, application of remote sensing (RS) data for inventory of coffee plantations has shown lower classification accuracy (CorderoSancho and Sader, 2007) due to complex cultivation practices. In the context of coffee, there are limited studies for utilising RS data (Miguel et al., 2012; Bernardes et.al, 2012). Advanced object oriented classifiers have shown some promising results for classification of high resolution data. (Mueller et al., 2004, Bock et al., 2005, and Gamanya et al., 2007). Hebbar et al., 2012 evaluated object oriented classification of high resolution satellite images for inventory of fruit and plantation crops. Kasper Johansen et al., 2009 showed the utility of high resolution data for delineation of banana plantations using a combination of object based classification and post classification visual editing.

There is a need for systematic and periodic inventory of coffee plantations in the country due to non-availability of reliable regional and national database after deregulation. In this context, a joint collaborative pilot study between Coffee Board and ISRO was initiated for inventory of coffee plantations in six traditional coffee growing talukas spread across Karnataka, Kerala and Tamil Nadu using high resolution satellite data. The study was initiated as a first step towards establishing standard methodology for inventory of coffee plantations and their spatial distribution using geospatial technology (RRSC-S, 2016). Based on the encouraging results of the pilot study, national level project was initiated to generate geospatial database on coffee plantations covering three major coffee growing regions of the country using high resolution satellite images.

\section{MATERIALS AND METHODS}

\subsection{Study Area}

The study area covered the traditional, non-traditional and north-eastern coffee growing regions of the country. Major coffee growing regions in India can be grouped under three distinct types a) Traditional areas representing the southern states of Karnataka, Kerala and Tamil Nadu; b) Non-traditional coffee growing areas comprising of Andhra Pradesh and Orissa in the Eastern Ghats of the country and c) the North Eastern region comprising the states of Assam, Manipur, Meghalaya, Mizoram, Tripura, Nagaland and Arunachal Pradesh. The study area includes three coffee growing regions of India, as it is essentially, inventory of coffee plantations at national level. The coffee plantations in the south are the cradle of Indian coffee. They include the Bababudangiri hills in Karnataka, known as the birthplace of coffee in India. The Eastern Ghats and the North Eastern states are recently developed new areas of coffee cultivation.

\subsection{Satellite and ancillary data}

Multi-resolution remote sensing data from three different satellites viz., Cartosat-1, Resourcesat-1 and Resourcesat-2 have been used in the present study for inventory of coffee plantations. As coffee plantations co-exist with forest and other vegetation categories in different study areas; multi-date IRS LISS-III data $(24 \mathrm{~m})$ was used to study phenology of different vegetation categories in Vythiri taluka (Wayanad district, Kerala). A total of 19 LISS-III multi-date images were used for phenology studies. 57 Resourcesat-LISS-IV scenes $(5.8 \mathrm{~m})$ and 168 Cartosat- 1 scenes $(2.5 \mathrm{~m})$ of recent years (2016-2018) have been utilized to cover the major coffee growing regions of the country.

In addition to the above satellite datasets, the following ancillary data from different sources and digital devices have been used either directly, or as reference and for field data collection in the study:

- Digital Elevation Model (10m) from Cartosat-1 stereo pairs for ortho-rectification

- Legacy vector data on roads, settlements, village boundaries from NRIS database

- Revenue village wise details and Coffee Board statistics on coffee area and production

- Cadastral maps for selected villages from Coffee Board

- Survey of India (SOI) toposheets on 1:50,000 scale

- Reserved forest area boundary

- Geo locations and geo-tagging of sample sites using hand held GPS device

- Digital camera for taking ground photos and laptop for field data collection

- Relevant image processing and GIS Software packages

\subsection{Methodology}

The broad methodology consisted of selection of optimum satellite data, processing of satellite datasets, ground truth collection and analysis of satellite data for delineation of coffee plantations. Selection of optimum window for data procurement was done based on the phenology of different vegetation existing in the study area. The image processing steps consisted of ortho-rectification, radiometric normalization, generation of NDVI and fusion of multisource data. Ortho-rectification of the datasets was carried out using DEM using photogrammetric bundle block adjustment. Vegetation indices were generated from LISS-IV data for its subsequent use in the classification. Fusion of orthorectified LISS-IV and Cartosat-1 data was carried out using standard data merging technique. In-season ground truth was used for analysis of satellite data for delineation of coffee plantations. Intensive ground truth representing the overall diversity in coffee cultivation was collected at 9387 sample locations including 2242 geotagged field photographs. Digital classification and visual interpretation techniques were employed for generating the spatial extent of coffee plantations at sub-district levels (talukas).

The spectral signature of coffee plantations in the study areas was complex due to varying shade tree composition, its density and terrain conditions. Digital classification or visual interpretation approaches was adopted depending on the suitability for achieving acceptable accuracy. Object-oriented classification method using eCognition was explored in case of homogeneous areas while visual interpretation was employed in heterogeneous areas. In-season field data and local expert knowledge of the liaison officials of Coffee Board played a 
critical role in achieving the reasonable mapping accuracy. Typical spectral signature of coffee plantations in homogeneous and heterogeneous areas is depicted in Figure-1.

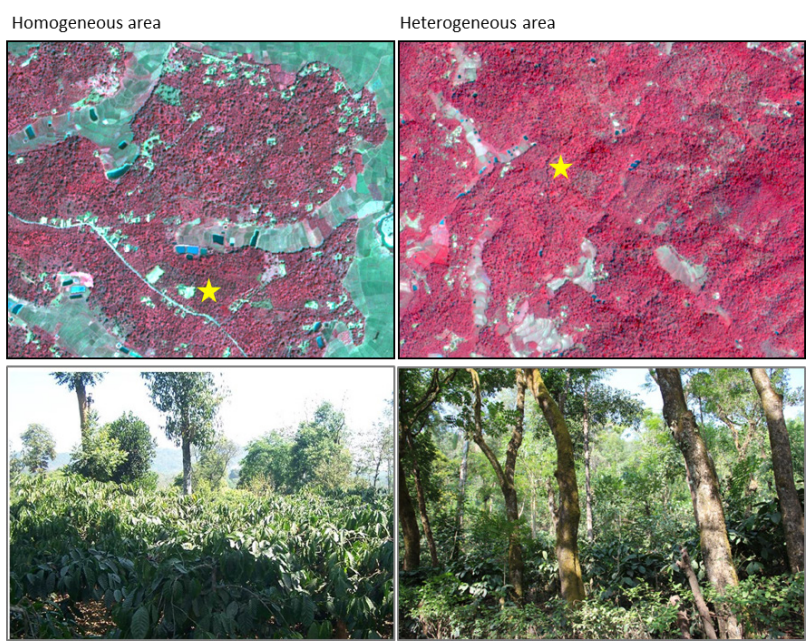

Figure-1. Spectral signature of coffee plantations in homogeneous and heterogeneous situations

For object based classification, LISS-IV and Cartosat-1 data along with NDVI was used as source data for multiresolution segmentation. Optimizing the segmentation parameters in terms of scale, shape and compactness was carried out iteratively based on visual inspection of the segmented images and finally scale parameter of 20 was selected. Hierarchical rule sets were defined using mean layer values and NDVI for generation of vegetation layer to use it as mask for classification. Training samples were identified for coffee and other vegetation classes based on the field information. Image object parameters such as mean, standard deviation, NDVI, geometry and other contextual parameters were analysed and feature space optimization function was used for selection of image features for classification. 14 image features consisting of mean, standard deviation, NDVI and geometry were selected for classification adopting SVM algorithm. The classified image obtained from the object oriented classification was generalised and tested using visual interpretation technique for one selected study area for accuracy assessment.

Field validation of coffee plantation map for each taluka was carried out for estimating post classification / interpretation accuracy in terms of mapping accuracy. The quality of final maps were audited by expert team consisting of liaison officials of Coffee Board having extensive local knowledge which helped in refinement of the maps to generate coffee map at national level. Finally, taluka-wise coffee acreage statistics were extracted and aggregated at district, state and national level and compared with officials statistics of Coffee Board.

\section{RESULTS AND DISCUSSION}

\subsection{Spectral Signature}

Majority of the coffee crop in the country is cultivated under shade trees. Detailed analysis was carried out to study the spectral response of coffee and other vegetation types. The coffee plantations manifested as different tones of red and mottled texture on high resolution data due to evergreen nature of both coffee and shade trees. Spectral signatures of coffee plantations determined by relative age category, composition of shade trees and terrain characteristics. The spectral signature of pure and mono shaded coffee plantations was quite distinct from other plantation categories such as coconut, arecanut, silver oak, acacia etc. Coffee plantations also co-exist with many other vegetation categories as represented in Figure-2. It is evident from the figure that

typical coffee plantation appeared as brownish red to deep red with mottled appearance basically due to the presence of interspersed shade trees. It was also observed that the texture pattern depended on shade tree density and composition. In India, coffee plantations typically exists at higher altitudes and across all slope categories except in very steep slopes. Similar complex spectral response of coffee plantations was reported earlier (Vieira et al., 2006)

In comparison to this, coconut plantations are generally cultivated along valleys and gently sloping lands and are well managed thus appearing as red to deep red in colour with clear row patterns on HRS data. Tea plantations cultivated at higher altitudes and across varying slope categories, were characterised by a relatively smoother texture with light to bright pink colour. Areca plantations are highly diverse and the spectral signature characterised by dark pink to brown colour with finer roughness. Banana plantation manifested in smooth bright reddish tone associated with distinct field boundaries reflective of broad leaves and intensive crop management. Rubber plantations appeared as light green to bright green during defoliation stage and dark red to light brown colour with smooth texture in refoliation stage. Pure silver oak plantations appeared as dark brownish red with a smooth granular texture. Spectral signature of coffee plantations under mixed shade trees is often confusing with forest and thus, delineation of coffee plantations was quite challenging in such cases. The coffee plantations in terms of distribution and spatial extent varied widely across the different coffee growing regions of India and thus, its interpretation using satellite data is quite challenging.

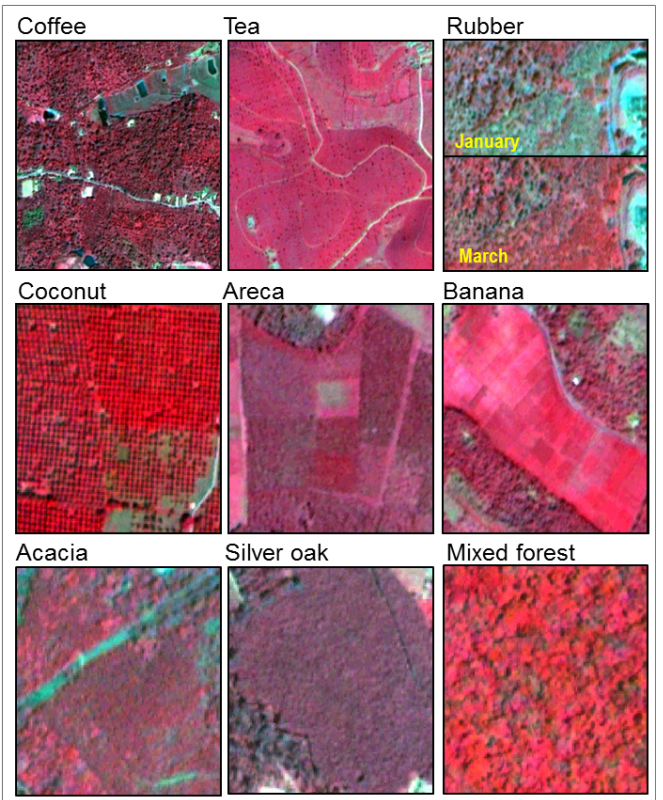

Figure-2. Spectral signatures of coffee plantations and other associated vegetation categories

\subsection{Classification}


The visual interpretation technique would be the appropriate method for mapping of coffee plantations to achieve better results considering the complex spectral signature. However, the interpretation is tedious, time consuming and requires both human \& computer resources for mapping at national scale. Hence, depending on the spectral characteristics and extent of coffee plantations \& other competing crops in each study area, digital or visual interpretation technique was adopted. The study talukas were grouped into two categories 1) Talukas with homogeneous and contiguous patches of coffee plantations with uniform spectral signature. These regions are also characterised by the presence of vast expanses of agricultural landscape and reserved forests which are spatially independent and 2) heterogeneous areas having sparse distribution of coffee plantations with mixed spectral signature, varying terrain and diverse shade tree composition and forest lands. About 40 per cent of the study area belonged to first category while rest of the area in second category.

In case of homogeneous areas, object based classification with 14 image features using SVM algorithm using was adopted for delineation of coffee plantations. The comparative analysis between visual interpretation and object based classification was carried out for accuracy assessment for one selected study area (Figure-3). The results showed that the committed error was about 14.2 per cent which is mainly due to spectral similarity of forest and coffee cultivated under mixed shade trees. The mis-interpretation of coffee plantations along the field boundary / fringes was noticed due to the mixed pixels resulting in omitted error of about 10.4 per cent. Thus, an overall accuracy of 75.4 per cent could be achieved from object based classification. Earlier studies have also reported about 75-80 per cent accuracy for mapping of coffee plantations due to similar spectral signature of coffee and other vegetation types (Lisa et al., 2018, Miguel et al., 2012 and Bouma \& Kobryn, 2004). The maps were further refined using visual interpretation to achieve better than 90.0 per cent accuracy.

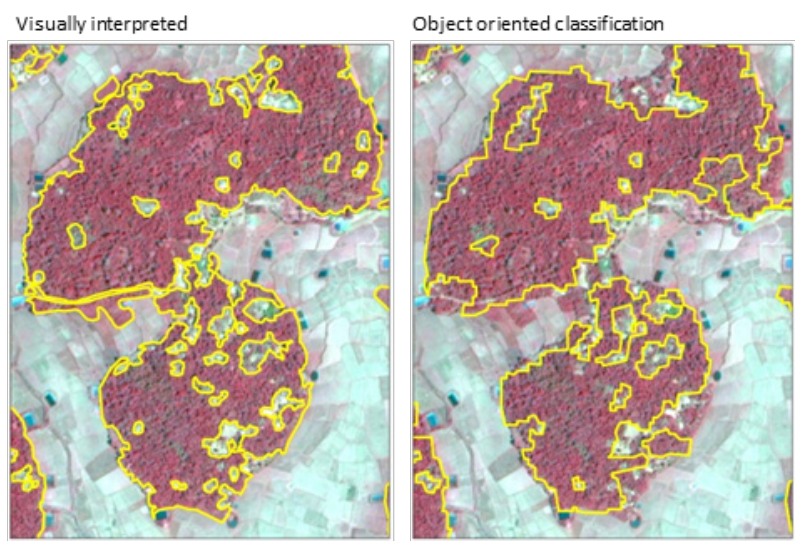

Figure-3: Comparison of coffee maps derived from visually interpreted and object based classification

Similar classification scheme adopted in the heterogeneous areas showed very poor classification accuracy and post classification refinement of the map was time consuming and tedious. Hence, onscreen visual interpretation using GIS was carried out for about 60 per cent of the study area. Ancillary data in the form of very high resolution satellite data, reserved forest area mask, topographical maps, DEM and field knowledge was used for improving the interpretation in these areas to achieve better than 92.0 per cent overall accuracy.

\subsection{Acreage estimation}

The classified / interpreted coffee maps at taluka level were spatially integrated at district and state level to generate coffee map at national level. The taluka-wise acreage was estimated from the consolidated maps and compared with official estimates obtained from Coffee Board (Table-1).

The details of analysis in various coffee growing regions of India are given below.

3.3.1 Traditional regions: Traditional coffee growing regions in India comprising southern states of Karnataka, Kerala and Tamil Nadu contribute about 91.5 per cent of the total area under coffee plantations. In these areas, typically coffee plantations are more contiguous occupying large extent. Karnataka state leads in total area under coffee cultivation and accounts for about 68 per cent of the national share, followed by Kerala $(15.3 \%)$ and Tamil Nadu (8.2\%).

\begin{tabular}{|c|c|c|c|}
\hline $\begin{array}{c}\text { SI.N } \\
\text { o }\end{array}$ & $\begin{array}{l}\text { Coffee Region } \\
\text { / State }\end{array}$ & $\begin{array}{l}\text { Remote } \\
\text { Sensing } \\
\text { Estimates (ha) }\end{array}$ & $\begin{array}{l}\text { Reported } \\
\text { area (ha) }\end{array}$ \\
\hline $\mathbf{A}$ & \multicolumn{3}{|c|}{ Traditional coffee growing regions } \\
\hline 1 & Karnataka & $3,00,159$ & $2,49,121$ \\
\hline 2 & Tamil Nadu & 36,915 & 34,483 \\
\hline \multirow[t]{2}{*}{3} & Kerala & 67,453 & 78,829 \\
\hline & Sub-Total & $4,03,897$ & $3,62,433$ \\
\hline B & \multicolumn{3}{|c|}{ Non-traditional coffee growing regions } \\
\hline 4 & $\begin{array}{l}\text { Andhra } \\
\text { Pradesh }\end{array}$ & 33,177 & 71,355 \\
\hline 5 & Odisha & 3,919 & 3,854 \\
\hline & Sub-Total & 37,096 & 75,209 \\
\hline & TOTAL & $4,40,993$ & $4,39,821$ \\
\hline
\end{tabular}

Table 1. State-level coffee acreage estimates

3.3.2 Non-Traditional regions: Non-traditional coffee growing regions account for about 8.0 per cent. They are mainly located in Andhra Pradesh \& Odisha states. The pedoclimatic conditions are more suitable for cultivation of Arabica coffee in the region. The coffee plantations in these regions was introduced by Integrated Tribal Development Agency (ITDA) to provide livelihood to the community. They are relatively new areas of coffee cultivation and relatively less contiguous with moderate density. Majority of the coffee parcels in Andhra Pradesh are located in and around Araku valley in Vishakhapatnam district accounting for about 7.5 per cent area under coffee cultivation. Coffee area in Odisha accounts only 0.8 per cent and located in parts of Koraput, Kalahandi and Rayagada districts.

3.3.3 North-Eastern (N-E) regions: Small and scattered plots of coffee plantations are available in North-Eastern states of Assam, Tripura, Meghalaya, Manipur, Mizoram, Nagaland, Arunachal Pradesh. N-E region contributes less than 0.5 per cent of national coffee area. The visual interpretation technique was used for mapping of coffee plantation in the region due to low spatial extent and sparse distribution.

The analysis showed about 4.41 lakh ha of coffee plantations at national level. Overall, the coffee area estimated from remote sensing is comparable with the official estimate. However, large deviations were observed at state level. The RS based coffee 
area was higher for Karnataka state while it was quite lower for Andhra Pradesh in comparison to Coffee Board estimates. In addition to inventory of coffee plantations, site suitability analysis has been carried out using pedo-climatic variables along with land use / land cover map to identify potential areas for cultivation of coffee in the non-traditional regions of the country.

\section{CONCLUSIONS}

The present study demonstrated the utility of geospatial technology for inventory of coffee plantations across diverse traditional coffee growing regions with acceptable accuracy. High resolution LISS-IV+Cartosat-1 data was used for mapping coffee plantations with better than 90.0 per cent overall accuracy at national level. The object based classification scheme adopted for the homogeneous areas showed about 75.0 per cent accuracy which could be further improved by visual interpretation. The machine learning techniques could be evaluated for improving classification accuracy. In this regard, ancillary data such as slope, aspect and weather parameters could be used as input data in the machine learning models to develop semi-automated classification scheme. This is the first study in the country to utilise remote sensing to generate coffee map at national level for creation of baseline geospatial database which could be updated periodically as per the requirement of Coffee Board. The database shall go a long way in meeting the requirements of Coffee Board in their operational planning and developmental activities. The scope of the study was also enhanced to include the site-suitability analysis for identification of potential areas for expansion of coffee cultivation in the non-traditional areas. After successfully accomplishing the challenging task of mapping of coffee plantations, few relevant issues need to be addressed such as discrimination of coffee types, shade tree types \& density, production estimation, pest and diseases etc. Research in hyperspectral, microwave techniques along with advanced data analytics need to be explored in this regard.

\section{ACKNOWLEDGEMENTS}

The project is funded by Coffee Board of India, Ministry of Commerce \& Industry for generation of geospatial data on coffee plantations at national level. The project team acknowledges extensive technical and field support received from the project scientists and field staff of Coffee Board in successful completion of the study. The authors are grateful to Director, National Remote Sensing Centre, ISRO, Hyderabad for providing valuable guidance and support for carrying out the study.

\section{REFERENCES}

1. Bernardes T., Moreira, M A., Adami, M., Giarolla A and Rudorff, BFT. 2012. Monitoring biennial bearing effect on coffee yield using MODIS remote sensing imagery. Special Issue on Advances in Remote Sensing of Agriculture, pp. 2492-2509.

2. Bock, M., P. Xofis, J. Mitchley, G. Rossner, and M. Wissen, 2005. Object-oriented methods for habitat mapping at multiple scales - Case studies from Northern Germany and Wye Downs, UK J. for Nature Conservation, 13:75-89.

3. Bouma, G.A. and Kobryn, H.T., 2004, Change in vegetation cover in East Timor, 1989-1999. Natural Resources Forum, 28, pp. 1-12

4. Coffee Board, 2018. http://www.indiacoffee.org.

5. Cordero-Sancho, S. and SADER, S.A., 2007. Spectral analysis and classification accuracy of coffee crops using Landsat and a topographic-environmental model. Int. J. of Remote Sensing, 28, pp. 1577-1593.

6. Gamanya, R., P.D. Maeyer, and M.D. Dapper, 2007. An automated satellite image classification design using objectoriented segmentation algorithms: A move towards standardization, Expert Systems with Applications, 32:616624.

7. Hebbar R., Ravishankar H.M., Shivam Trivedi, Uday Raj and Dadhwal V.K., 2014. Object oriented classification of high-resolution data for inventory of horticulture crops. The International Archives of the Photogrammetry, Remote Sensing and spatial Information Sciences, Vol. XL-VIII, 2014; ISPRS Technical Commission VIII Symposium, 0912 Dec.2014, Hyderabad, India.

8. Kasper Johansen, Stuart Phinn, Christian Witte, Seonaid Philip, and Lisa Newton, 2009. Mapping Banana Plantations from Object-oriented Classification of SPOT-5 Imagery. PE\& RS, Vol. 75, No. 9, pp. 1069-1081.

9. Komar O., 2006. Ecology and conservation of birds in coffee plantations: a critical review. Bird Conservation International, 16, pp. 1-23.

10. Lisa C. Kelley, Lincoln Pitcher and Chris Bacon., 2018, Using Google Earth engine to map complex shade-grown coffee landscapes in northern Nicaragua, Remote Sens. 10, 952; doi:10.3390/rs10060952, pp:1-19

11. Mueller, M., K. Segl, and H. Kaufmann, 2004. Edge- and region-based segmentation technique for the extraction of large, man-made objects in high-resolution satellite imagery, Pattern Recognition, 37:1619-1628.

12. Moguel, P. and Toledo, V.M., 1999. Review: Biodiversity conservation in traditional coffee systems of Mexico. Conservation Biology, 13, p. 11-21.

13. Miguel, A.O.H., Oliver Komar, Kevin P. Price and Hugo J. Ventura, 2012. Mapping coffee plantations with Landsat imagery: an example from El Salvador, Int. J. of Remote Sensing, 33:1, 220-242

14. Perfecto I., R. Rice, R. Greenberg, and M. E. Van der Voort. 1996. "Shade coffee: A disappearing refuge for biodiversity." Bioscience 46(8): 598-608.

15. RRSC-S, 2016. Inventory of Coffee Plantations using Geospatial Technology: Pilot study in traditional coffee growing regions of India, NRSC-RC-APR-2016-TR-842, pp:1-150. 
16. Vieira T. G. C, Alves, H. M. R., Lacerda, M. P. C., Veiga, R. D., and J. C. N. Epiphanio, 2006, Crop parameters for the evaluation of the spectral response of coffee (Coffea arabica) areas within the state of Minas Gerais, Brazil, Coffee Science, Lavras, Vol. 1, No. 2, pp: 111-118. 